\title{
Reviewers: Behavioural Public Policy 2018
}

Behavioural Public Policy depends on its reviewers to maintain and improve the quality of the articles that it publishes. The Editorial Board is very grateful to the following, who have acted as reviewers, sometimes more than once.

Maja Adena, Berlin Social Science Center, Germany.

Richard Ashcroft, Queen Mary University, London, UK.

Kate Barasz, IESE Business School, Madrid, Spain.

Giorgia Barboni, Princeton University, USA.

Gwyn Bevan, London School of Economics and Political Science, UK.

Toby Bolsen, Georgia State University, USA.

Luc Bovens, University of North Carolina at Chapel Hill, USA.

Adam Butt, Australian National University, Australia.

Leigh Caldwell, Inon Pricing Advisers, UK.

Adam Carter, Monash University, Australia.

Gordon Clark, University of Oxford, UK.

Christine Clavien, University of Geneva, Switzerland.

Sarah Conly, Bowdoin College, Brunswick, USA.

Wojciech Cwalina, SWPS University of Social Sciences and

Humanities, Poland.

Padraig Dixon, University of Bristol, UK.

James Edwards, University of Chicago, USA.

Emir Efendic, Technische Universiteit Eindhoven, Netherlands.

Martin Fochmann, University of Köln, Germany.

Eleonora Freddi, Tilburg University, Netherlands.

Varun Gauri, The World Bank, USA.

Denis Griffin, Auckland University of Technology, New Zealand.

Till Grüne-Yanoff, KTH Royal Institute of Technology, Sweden.

Pelle Guldborg Hansen, Roskilde University, Denmark.

Nik Gurney, Carnegie Mellon University, USA.

Tony Hockley, London School of Economics and Political Science, UK.

Walter Hyll, Halle Institute for Economic Research, Leibniz, Germany.

Peter John, King's College London, UK.

Satoshi Kanazawa, London School of Economics and Political Science, UK.

Uma Karmarker, Harvard University, USA. 
Warut Khern-am-nuai, McGill University, Canada.

Leonhard Lades, University of Stirling, UK.

Craig McKenzie, University of California San Diego, USA.

Sara Machado, London School of Economics and Political Science, UK.

Peter Matthews, Middlebury College, USA.

Barbara Mellers, University of Pennsylvania, USA.

Philippe Mongin, Centre National de la Recherche Scientifique, France.

Kristian Roed Nielsen, Copenhagen Business School, Denmark.

Jessica Nolan, University of Scranton, USA.

Vanessa Perry, George Washington University, USA.

Jessica Pykett, University of Birmingham, UK.

Matthew Quaife, London School of Hygiene and Tropical Medicine, UK.

Ellen Peters, Ohio State University, USA.

Karen Richman, University of Notre Dame, USA.

Scott Ruoti, Massachusetts Institute of Technology, USA.

Sunita Sah, Cornell University, USA.

Anya Samek, University of Southern California, USA.

Ian Schneider, Massachusetts Institute of Technology, USA.

Mary Steffel, Northeastern University, USA.

Robert Sugden, University of East Anglia, UK.

Nynke van der Laan, University of Amsterdam, Netherlands.

Kaitlin Woolley, Cornell University, USA.

Horst Zank, University of Manchester, UK. 